\title{
Agôn
}

Revue des arts de la scène

Critiques | Saison 2011-2012

\section{Le Moukden Théâtre ou l'expérience de la dialectique}

\section{Alice Carré}

\section{(2) OpenEdition}

Journals

Édition électronique

URL : http://journals.openedition.org/agon/2187

DOI : $10.4000 /$ agon. 2187

ISSN : 1961-8581

\section{Éditeur}

Association Agôn

\section{Référence électronique}

Alice Carré, "Le Moukden Théâtre ou l'expérience de la dialectique », Agôn [En ligne], Critiques, mis en ligne le 16 février 2012, consulté le 23 septembre 2020. URL : http://journals.openedition.org/agon/ 2187 ; DOI : https://doi.org/10.4000/agon.2187

Ce document a été généré automatiquement le 23 septembre 2020

Association Agôn et les auteurs des articles 


\title{
Le Moukden Théâtre ou l'expérience de la dialectique
}

\author{
Alice Carré
}

\section{RÉFÉRENCE}

Pierre ou les Ambiguïtés, D’après Pierre ou les Ambiguïtés et L'Escroc à la Confiance d'Herman Melville Par le Moukden Théâtre, Mise en scène : Olivier Coulon-Jablonka, Adaptation : Eve Gollac et Olivier Coulon-Jablonka

Rares sont ceux qui se risquent à l'adaptation des œuvres d'Herman Melville à la scène. Si l'on a pu voir en 2007 Moby Dick dans une mise en scène d'Antonio Latella, l'essentiel des artistes choisissent la forme de la lecture, tel Daniel Pennac avec Bartleby le Scribe en 2009. Olivier Coulon-Jablonka et le Moukden Théâtre se livrent ici à un véritable travail de théâtralisation du roman fleuve de l'auteur américain Pierre ou les Ambiguités, qui grâce à l'enchevêtrement de passages de L'Escroc à la Confiance, prend une dimension politique et philosophique d'une grande acuité et s'attache à débusquer quelques uns des présupposés des idéologies contemporaines. 
Pierre ou les ambiguïtés du Moukden théâtre.

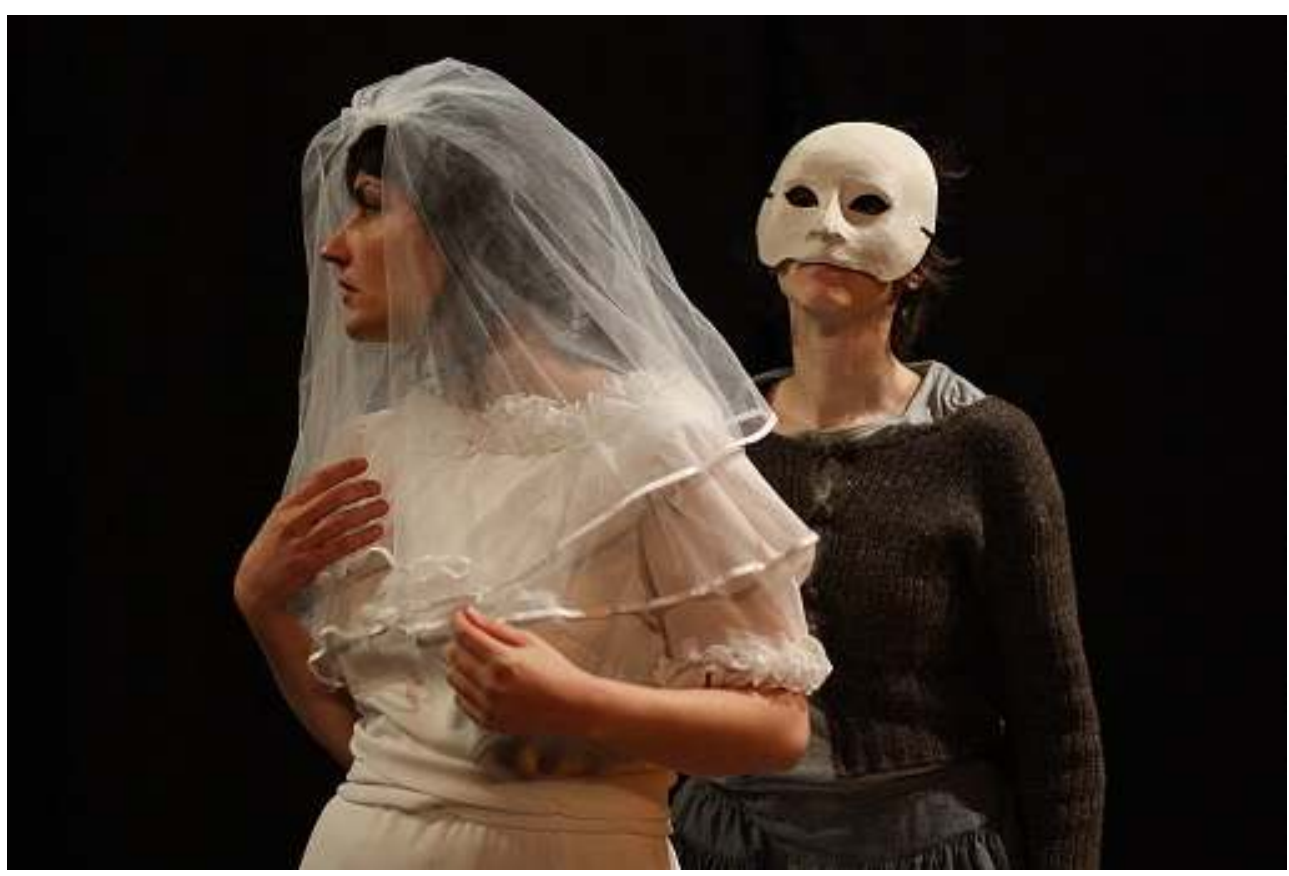

(c) Marine Fromanger

2 Les deux textes s'éclairent l'un l'autre, et la question de la confiance, qu'elle soit économique, politique ou intime, devient la pierre de touche des questionnements d'aujourd'hui. La foi accordée par Pierre Glendinning, héritier du manoir de Saddle Meadows, à Isabelle, parfaite inconnue, qui lui demande, au nom de " mystérieuses coïncidences ", de croire qu'elle est sa sœur, semble douteuse. Quelles qu'en soient les raisons : amour incestueux qui lie les deux personnages, soif d'héroïsme, la confiance idéale en l'autre s'escamote peu à peu et Pierre apparaît comme le paradigme du doute naissant. La méfiance généralisée a pris la place de la confiance en l'autre, l'absence de crédulité a remplacé l'héroïsme, le cynisme a battu en brèche l'idéalisme. Le capitalisme et la confiance qu'il suppose de la part de celui qui veut faire fructifier son bien et s'en remet à des organismes compétents, questionné par des extraits de la L'Escroc à la Confiance, vient donc se poser en regard des choix étonnants de Pierre qui tourne le dos à son héritage, salit sa réputation, compromet son bonheur, pour donner à sa sœur présumée la place qu'elle mérite dans son cœur.

Le travail d'adaptation mené par Eve Gollac et Olivier Coulon-Jablonka met la réflexivité au cœur du spectacle et adopte un certain nombre de procédés brechtiens, réinjectant le débat au cœur de la narration. Le Moukden Théâtre a pris son nom de la ville où se déroule l'action de La Décision de Brecht, choisissant de revendiquer l'héritage d'un théâtre politique, d'un type de jeu où l'acteur, conscient des idéaux sous-jacents du texte, exerce son esprit critique et n'est jamais le pur instrument d'une mise en scène. Servant d'écho aux aventures romanesques et de distance par rapport à l'univers bourgeois qui jalonne le texte, un chœur de deux narrateurs commente, interrompt les scènes de rires faussement étouffés et met l'action en question. Les voici donc brandissant un livre, Hamlet de Shakespeare, « Ne lisez pas ça !", s'exclament-ils. La pièce de l'inaction, la "tragédie du désir ", selon Lacan, limiterait l'homme à une impossibilité de changer son destin. Avec Pierre, l'action est menée tambour battant, dans une radicalité que ses premières incertitudes ne laissaient pas présager. Peut-être 
le modèle de l'action à outrance qui domine le XXe siècle plongerait ses racines dans ce retournement là, le " just do it ", l'action recouvrant même le questionnement du comment agir, du bilan et de la réflexion. Ce que nous dit le Moukden est alors ceci : le XXIe siècle aurait renoncé à l'action fracassante de ses prédécesseurs, et aurait remplacé la gloire de l'action par le cynisme, réduisant l'individu à un spectateur désemparé de l'histoire.

4 La force de la mise en scène est de faire de ces incartades philosophiques non pas une série de parenthèses cérébrales greffées au spectacle, mais au contraire une matière scénique à part entière. Ces séquences dialoguées, menées par ces deux excentriques choreutes qui parasitent la narration, débattent champagne en main et chapeau pointu sur la tête quand le héros s'enfonce dans le désespoir, deviennent les moments d'une diversion humoristique de la pensée qui permettent à la fois de rendre plus digestes les aventures torturées de Pierre, et de mettre en perspective les idées soulevées par celles-ci. Ainsi, les esclaffements des deux acteurs permettent d'instaurer une distance vis-à-vis des scènes initiales de la vie bourgeoise, jouées en costumes fidèles au XIXe siècle, déjà décalées par les regards fréquents et inquisiteurs des acteurs vers le public. Même si la mise en scène choisit de respecter le cadre temporel du roman, le but est bien de parler du présent, et la mise en scène s'emploie avec brio à prêter au théâtre une vraie fonction dialectique.

Du 6 au 25 février au Théâtre de l'échangeur, Bagnolet : Renseignements : http:// www.lechangeur.org/, 0143627120 - Du 29 février au 2 mars Théâtre La Vignette, Montpellier - Du 27 au 29 mars 2012 Nouveau Théâtre, CDN de Besançon.

\section{INDEX}

Mots-clés : Pierre ou les Ambiguïtés, Moukden Théâtre, Coulon-Jablonka (Olivier) 